\title{
Undetectable HCV-RNA at treatment-week 8 results in high-sustained virological response in HCV G1 treatment- experienced patients with advanced liver disease: the International Italian/Spanish Boceprevir/Peginterferon/ Ribavirin Name Patients Program
}

\author{
S. Bruno, ${ }^{1}$ S. Bollani, ${ }^{1}$ A. L. Zignego, ${ }^{2}$ J. M. Pascasio, ${ }^{3}$ C. Magni, ${ }^{4}$ A. Ciancio, ${ }^{5}$ M. Caremani, ${ }^{6}$ \\ A. Mangia, ${ }^{7}$ S. Marenco, ${ }^{8}$ S. Piovesan, ${ }^{9}$ L. Chemello, ${ }^{10}$ S. Babudieri, ${ }^{11}$ A. Moretti, ${ }^{12}$ F. Gea, ${ }^{13}$ \\ C. Colletta, ${ }^{14}$ R. Perez-Alvarez, ${ }^{15}$ X. Forns, ${ }^{16} \mathrm{~J}$. R. Larrubina, ${ }^{17} \mathrm{~J}$. Arenas, ${ }^{18} \mathrm{~J}$. Crespo, ${ }^{19}$ \\ V. Calvaruso, ${ }^{20}$ F. Ceccherini Silberstein, ${ }^{21}$ P. Maisonneuve, ${ }^{22}$ A. Craxì, ${ }^{20}$ J. L. Calleja ${ }^{23}$ and \\ Italian and Spanish (IAS)-BoC Study Group* ${ }^{1}$ AO Fatebenefratelli e Oftalmico, Milano, Italy; ${ }^{2}$ Università di Firenze, Firenze. \\ Italy; ${ }^{3}$ Hospital Universitario Virgen del Rocio, Sevilla, Spain; ${ }^{4}$ AO L. Sacco, Milano, Italy; ${ }^{5}$ Università di Torino, Torino, Italy; ${ }^{6}$ AO di Arezzo, Arezzo, \\ Italy; ${ }^{7}$ IRCCS Casa del Sollievo e della Sofferenza, S. Giovanni Rotondo, Italy; ${ }^{8}$ Università di Genova, Genova, Italy; ${ }^{9}$ Università di Padova, Padova, Italy; \\ ${ }^{10}$ Università di Padova, Padova, Italy; ${ }^{11}$ Università di Sassari, Sassari, Italy; ${ }^{12}$ AO S. Filippo Neri, Roma, Italy; ${ }^{13}$ Hospital U. La Paz, Madrid, \\ Spain; ${ }^{14} \mathrm{COQ}$ Ospedale Madonna del Popolo, Omegna, Italy; ${ }^{15}$ Hospital Universitario Central De Asturias, Oviedo, Spain; ${ }^{16}$ Hospital Clinic, Barcelona, \\ Spain; ${ }^{17}$ Hospital Universitario De Guadalajara, Guadalajara, Spain; ${ }^{18}$ Hospital Donostia, Donostia, Spain; ${ }^{19}$ Hospital Universitario Marques de \\ Valdecilla, Santander, Spain; ${ }^{20}$ Università di Palermo, Palermo, Italy; ${ }^{21}$ Università di Roma Tor Vergata, Roma, Italy; ${ }^{22}$ Istituto Europeo di \\ Oncologia, Milano, Italy; and ${ }^{23}$ Hospital Universitario Puerta de Hierro, Madrid, Spain
}

Received July 2014; accepted for publication September 2014

SUMMARY. In many countries, first-generation protease inhibitors (PIs)/peginterferon/ribavirin (P/R) still represent the only treatment option for HCV-infected patients. Subjects with advanced disease and previous failure to $P / R$ urgently need therapy, but they are under-represented in clinical trials. All treatment-experienced F3/4 Metavir patients who received boceprevir (BOC) $+\mathrm{P} / \mathrm{R}$ in the ItalianSpanish Name Patient Program have been included in this study. Multivariate logistic regression analysis (MLR) was used to identify baseline and on-treatment predictors of SVR and adverse events (AEs). Four hundred and sixteen patients, mean age 57.7 (range 25-78 years), 70\% males, 69.5\% (289/416) F4, 14\% (41/289) Child-Pugh class A6, $24 \%(70 / 289)$ with varices and $42 \%$ (173/416) prior null responders to $\mathrm{P} / \mathrm{R}$, were analysed. Overall, SVR rate (all 381 patients who received one dose of BOC) was $49 \%$, (58\% in $\mathrm{F} 3,45 \%$ in $\mathrm{F} 4,61 \%$ in relapsers, $51 \%$ in partial, $38 \%$ in null responders, and $72 \%$ in subjects with undetectable HCV-RNA at treatment-week (TW)8. Among patients with TW8 HCV-RNA $\geq 1000 \mathrm{IU} / \mathrm{L}$, SVR was $8 \%$ (negative predictive value $=92 \%$ ). Death occurred in 3 $(0.8 \%)$ patients, while decompensation and infections were observed in $2.9 \%$ and $11 \%$, respectively. At MLR, SVR predictors were TW4 HCV-RNA $\geq 1 \log _{10}$-decline from baseline, undetectable TW8 HCV-RNA, prior relapse, albumin levels $\geq 3.5 \mathrm{~g} / \mathrm{dL}$ and platelet counts $\geq 100000 / \mu \mathrm{L}$. Metavir F4, Child-Pugh A6, albumin, platelets, age and female gender were associated with serious and haematological AEs. Among treatment-experienced patients with advanced liver disease eligible for IFN-based therapy, TW8 HCV-RNA characterised the subset with either high or poor likelihood of achieving SVR. Using TW8 HCV-RNA as a futility rule, $\mathrm{BOC} / \mathrm{P} / \mathrm{R}$ appears to have a favourable benefit-risk profile.

Keywords: boceprevir, cirrhosis, first-generation protease inhibitors, hepatitis C, IFN-based therapy.

\footnotetext{
Abbreviations: AE, adverse event; BOC, boceprevir; CI, confidence interval; HCC, hepacellular carcinoma; HCV, hepatitis C virus; MLR, multivariate logistic regression; NNT, number needed to treat; P/R, peginterferon/ribavirin; RAVs, resistance-associated variants; SAE, serious adverse event; SVR, sustained virological response; TW, treatment week.
}

Correspondence: S. Bruno, Department of Internal Medicine, Fatebenefratelli e Oftalmico Hospital, Corso di Porta Nuova 21, 20121 Milan, Italy. E-mail: savino.bruno@fbf.milano.it

*Italian and Spanish (IAS)-BoC Study Group members are in Appendix 1. 


\section{INTRODUCTION}

Hepatitis C virus -infected patients with advanced fibrosis and cirrhosis still represent a therapeutic challenge in the era of direct acting antiviral agents (DAAs) because of lower SVR rates and poorer tolerability of therapy [1-6]. Nevertheless, a clear benefit in treating cirrhotic patients exists. In many cases, the urgency to treat their disease before they reach the decompensated stage (i.e. when IFNbased antiviral therapies become contraindicated), is still an unmet clinical need. In this rapidly changing field, safer and more efficacious therapies are emerging, either with or without IFN [7-12]. Nevertheless, in a very large number of countries worldwide, first-generation protease inhibitors (PIs), combined with the IFN-based regimen, remain the only available option for these patients. To date, Boceprevir (BOC) has been approved and marketed in 67 countries (only 28 in 2013 and 1 in 2014) while it has been approved, but not marketed yet in 14 other countries. As a result, it is conceivable to speculate that, due to cost-containment policies or limited economic resources, new DAAs will not be affordable soon either. However, while waiting for new molecules, pivotal phase-3 clinical trials on BOC, which included a small sample size of patients with cirrhosis and only a few with both null response and advanced disease $[3,6,13,14]$, resulted in insufficient data regarding maximum utilization of BOC. Therefore, useful information to guide clinicians in daily practice is needed.

Overall risk to benefit ratio of $\mathrm{BOC} / \mathrm{P} / \mathrm{R}$ treatment in cirrhotic patients was analysed using expanded data from 5 Phase-3 clinical trials [15]. Specifically, this study identified baseline and on-treatment variables (in particular week 8 response) that could help predict response and guide clinical decisions regarding BOC triple therapy for cirrhotic patients, including decisions about discontinuation for futility [15]. As a matter of fact, this post hoc analysis included a carefully selected population with well-compensated disease and, again, a small number of patients with prior null response. Consequently, the results obtained in this study are not fully representative of the real-life population. Some data have indeed been obtained by the CUPIC study $[16,17]$, which evaluated triple combination regimens with either telaprevir or BOC in a wider range of treatmentexperienced cirrhotic patients (many of whom would not have qualified for pivotal trials). However, this study included a very small number of prior null responders, as well $[16,17]$. In addition, the safety profile reported in the CUPIC study was restricted, mainly due to the considerable number of included patients described as being incompatible with IFN-based regimens [18,19].

Here, we report a detailed analysis on the International BOC Name Patient Program (NPP), which was independently carried out in Italian and Spanish qualified Centres. This was the largest cohort of patients with advanced fibrosis/cirrhosis and prior null response ever studied. The information provided enhances the quality of BOC treatment and, therefore, allows better management of these patients while filling the time gap until the arrival of new drugs. By a detailed assessment of efficacy and safety in all different categories of patients, including the week 8 response value, as a predictor of SVR [15], we were able to assess the number needed to treat (NNT) for each SVR achieved.

\section{PATIENTS AND METHODS}

From March 2011 to September 2012, all treatment-experienced patients with HCV genotype $1 \mathrm{a}$ or $1 \mathrm{~b}$, advanced fibrosis and compensated cirrhosis with or without portal hypertension were enroled for this analysis. The patients were treated in 74 centres in the context of the NPP and each centre included at least three patients.

Baseline recorded data were: gender, age, histology, liver stiffness by FS, oesophageal varices, quantitative HCV-RNA with the Roche COBAS ${ }^{\circledR}$ TaqMan $^{\circledR}$ or Abbot assays with a lower limit of detection of 15 and $12 \mathrm{IU} / \mathrm{mL}$ [20,21], respectively, HCV genotype and IL28B polymorphism.

Clinical and virological assessments were performed every 4 weeks during therapy and at weeks 12 and 24 of the follow-up period. Futility rule was applied by label.

At the time of inclusion, patient disease stage was reevaluated by liver stiffness measurement and by endoscopy. Cirrhosis was defined on the basis of any one of the following criteria: (i) liver biopsy performed prior to Day 1 of the study showing cirrhosis consistent with Metavir score F4 or Ishak F5/6, (ii) presence of oesophageal varices and (iii) fibroScan, performed within 12 calendar months of Day 1 of the study, showing cirrhosis (liver stiffness $\geq 12.5 \mathrm{kPa}$ ) [22,23]. The diagnosis of advanced liver fibrosis was performed on the basis of any one of the following criteria: (i) liver biopsy, performed within 24 months of Day 1 of the study, showing fibrosis with Metavir score F3 or Ishak F3/4 and (ii) fibroScan, performed within 12 months of Day 1 of the study, showing liver stiffness $\geq 9.5$ and $\leq 12.5 \mathrm{kPa}$. In case of disagreement between previous histology (F3) and liver stiffness value, consistent with $\mathrm{F} 4$ at time of inclusion, the latter was considered the right one. Written informed consent was obtained from each patient before enrolment. The protocol was carried out in accordance with the Declaration of Helsinki and was approved by local Ethics Committees.

Safety assessment was carried out every 4 weeks with the recording of any AEs and serious AEs (SAEs; including deaths and hospitalizations), and AEs leading to study drug discontinuations. Laboratory assessments focused on anaemia, neutropenia and thrombocytopenia. EPO use and blood transfusions were also recorded. The following parameters were considered to potentially represent hepatic decompensation: onset of ascites, encephalopathy, bleeding 
from oesophageal varices, jaundice, and sepsis (in the context of declining liver function).

Virological failures and futility rules at week 12 and 24 were used according to the label.

Breakthrough was defined as an HCV-RNA $\geq 1 \log$ increase after an undetectable HCV-RNA. Relapse was defined as the onset of de novo detectable HCV-RNA after EoTR. SVR12 was defined as having undetectable HCV-RNA 12 weeks after completion or discontinuation of therapy.

\section{Statistical analysis}

The primary efficacy analysis was conducted on all patients who received at least 1 dose of $\mathrm{BOC} / \mathrm{P} / \mathrm{R}$, while SVR12 rates (overall and according to fibrosis stage on all patients who received at least 1 dose of $\mathrm{P} / \mathrm{R}$ during lead-in phase) were also provided. The relationship between baseline and on-treatment factors and SVR was explored using univariate and multivariate logistic regression analyses (MLR). We used a back-wise variable selection, and only variables for which the association remained statistically significant were included in the final multivariable logistic regression model. Stratified MLR analysis was also performed by fibrosis score. Analyses were performed with the SAS software (version 8.2; Cary, NC). All P-values were two-sided. $P<0.05$ was considered statistically significant.

\section{RESULTS}

\section{Patient accounting and baseline characteristics}

Four hundred and sixteen treatment-experienced patients with HCV genotype $1 \mathrm{a}$ or $1 \mathrm{~b}$ with advanced fibrosis or compensated cirrhosis were enroled from 74 centres, which enroled at least three patients in Italy and Spain. Baseline characteristics of the 416 enroled patients (overall and according to administration of BOC after the lead-in phase) are shown in Table 1. Briefly, 381 (92\%) patients received at least one dose of BOC. In the remaining cases $(8 \%)$, treatment was stopped before starting triple therapy due to poor tolerance to IFN and RBV. Mean age was 57.7 years (range 25-78). HCV genotype 1b (323/416, $77.6 \%$ ) was the prevalent genotype. The majority of patients $(289 / 416,69.5 \%)$ had $\mathrm{F} 4$ cirrhosis. In this latter group, Child classes A5 and A6 accounted for 85.4\% (240/416) and $14.6 \%$ (41/416) of patients, respectively; approximately, 25\% (70/289) had oesophageal varices, $13.2 \%(55 / 416)$ had platelet counts $\leq 100000 / \mu \mathrm{L}$ and $8.7 \%(34 / 416)$ had serum albumin levels $\leq 3.5 \mathrm{~g} / \mathrm{dL}$. Seven patients $(2.4 \%)$ in the F4 group had concurrent low albumin levels and low platelet counts. Regarding prior treatment history: $42 \%$ of patients (173/416) were null responders, $35 \%$ relapsers $(145 / 416)$ and $23 \%$ partial responders (96/416). IL-28B genotype was available for
Table 1 Baseline characteristics of 416 patients at study entry

\begin{tabular}{|c|c|c|c|c|}
\hline \multirow{2}{*}{$\begin{array}{l}\text { Patients } \\
\text { characteristics* }\end{array}$} & \multirow{2}{*}{$\begin{array}{l}\text { All patients } \\
N(\text { col. } \%)\end{array}$} & \multicolumn{2}{|c|}{$\begin{array}{l}\text { Received } \\
\text { boceprevir }\end{array}$} & \multirow{2}{*}{$\begin{array}{l}P- \\
\text { value }\end{array}$} \\
\hline & & No & Yes (row \%) & \\
\hline Total patients & 416 & 35 & 381 (91.6) & \\
\hline \multicolumn{5}{|l|}{ Country } \\
\hline Italy & $280(67.3)$ & 13 & $267(95.4)$ & \multirow[t]{2}{*}{0.0002} \\
\hline Spain & $136(32.7)$ & 22 & $114(83.8)$ & \\
\hline \multicolumn{5}{|l|}{ Gender } \\
\hline Male & $291(70.0)$ & 21 & $270(92.8)$ & \multirow[t]{2}{*}{0.18} \\
\hline Female & $125(30.0)$ & 14 & $111(88.8)$ & \\
\hline \multicolumn{5}{|l|}{ Age } \\
\hline$<50$ years & $116(28.4)$ & 13 & $103(88.8)$ & \multirow[t]{3}{*}{0.10} \\
\hline 50-59 years & $151(37.0)$ & 7 & $144(95.4)$ & \\
\hline$\geq 60$ years & 141 (34.6) & 14 & $127(90.1)$ & \\
\hline \multicolumn{5}{|l|}{ Metavir } \\
\hline F3 & $127(30.5)$ & 6 & $121(95.3)$ & \multirow[t]{2}{*}{0.08} \\
\hline $\mathrm{F} 4$ & $289(69.5)$ & 29 & $260(90.0)$ & \\
\hline \multicolumn{5}{|l|}{ Child class } \\
\hline A5 & $240(85.4)$ & 20 & $220(91.7)$ & \multirow[t]{2}{*}{0.04} \\
\hline A6 & $41(14.6)$ & 8 & $33(80.5)$ & \\
\hline \multicolumn{5}{|l|}{ Varices } \\
\hline No & $209(74.9)$ & 25 & $184(88.0)$ & \multirow[t]{2}{*}{0.37} \\
\hline Yes & $70(25.1)$ & 5 & $65(92.9)$ & \\
\hline \multicolumn{5}{|l|}{ FibroScan } \\
\hline$<12.5 \mathrm{kPa}$ & $131(36.9)$ & 8 & $123(93.9)$ & \multirow[t]{2}{*}{0.24} \\
\hline$\geq 12.5 \mathrm{kPa}$ & $224(63.1)$ & 23 & $201(89.7)$ & \\
\hline \multicolumn{5}{|l|}{ Albumin } \\
\hline $\begin{array}{l}\text { Low } \\
\qquad(\leq 3.5 \mathrm{~g} / \mathrm{dL})\end{array}$ & $34(8.7)$ & 6 & $28(82.4)$ & \multirow[t]{2}{*}{0.10} \\
\hline$>3.5 \mathrm{~g} / \mathrm{dL}$ & 357 (91.3) & 28 & $329(92.2)$ & \\
\hline \multicolumn{5}{|l|}{ Platelets } \\
\hline $\begin{array}{l}\text { Low } \\
\qquad(\leq 100000 / \mu \mathrm{L})\end{array}$ & $55(13.2)$ & 10 & $45(81.8)$ & \multirow[t]{2}{*}{0.02} \\
\hline$>100000 / \mu \mathrm{L}$ & $361(86.8)$ & 25 & $336(93.1)$ & \\
\hline \multicolumn{5}{|l|}{ Genotype } \\
\hline $1 b$ & $323(77.6)$ & 27 & $296(91.6)$ & \multirow[t]{2}{*}{1.00} \\
\hline $1 \mathrm{a}$ & $93(22.4)$ & 8 & $85(91.4)$ & \\
\hline \multicolumn{5}{|l|}{$\begin{array}{l}\text { Previous } \\
\text { response }\end{array}$} \\
\hline Relapser & $145(35.0)$ & 8 & $137(94.5)$ & \multirow[t]{3}{*}{0.15} \\
\hline $\begin{array}{l}\text { Partial } \\
\text { responder }\end{array}$ & $96(23.2)$ & 7 & $89(92.7)$ & \\
\hline Null responder & $173(41.8)$ & 20 & $153(88.4)$ & \\
\hline IL28 & & & & \\
\hline $\mathrm{CC}$ & $28(10.5)$ & 2 & $26(92.9)$ & 0.51 \\
\hline $\mathrm{CT}$ & $173(64.5)$ & 9 & $164(94.8)$ & \\
\hline TT & $67(25.0)$ & 6 & $61(91.0)$ & \\
\hline
\end{tabular}

*Some information is missing for few patients. Bold values are statistically significant. 

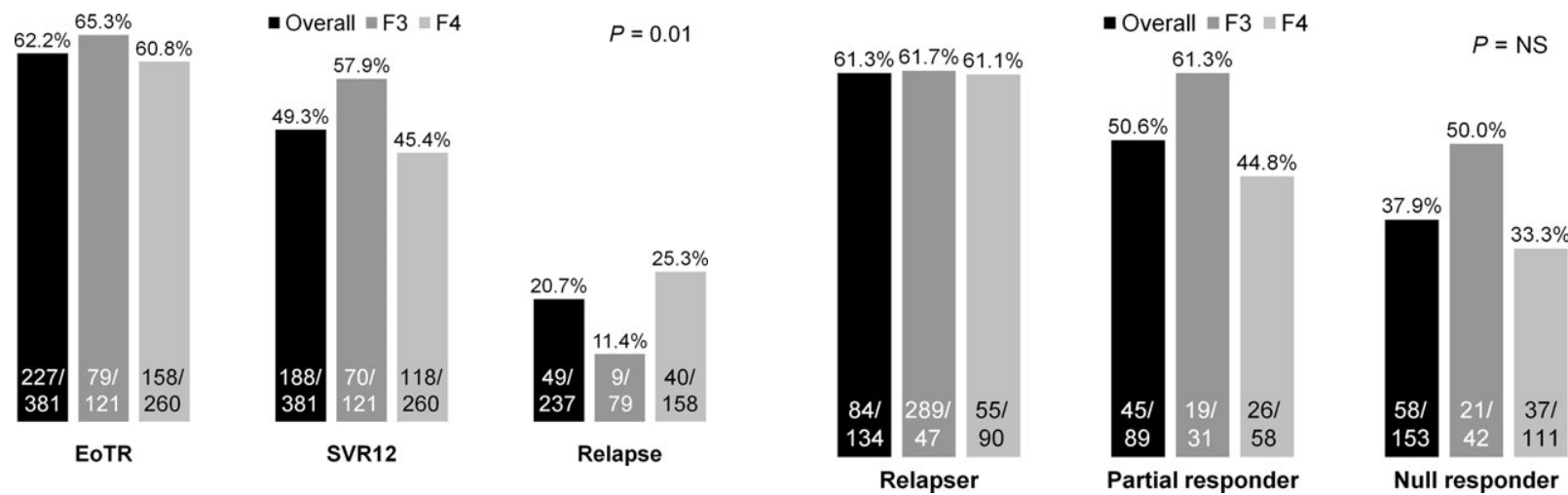

Fig. 1 EoTR, SVR12 and relapse rate overall and according to fibrosis stage. All patients who received at least one dose of BOC included in the study.

268 (64.4\%) patients. The CT genotype was the most prevalent $(64.5 \%)$ one. Table S1 shows the characteristics of the patients according to country of origin.

\section{Efficacy}

Overall, SVR12 rates on all enroled patients who received at least 1 dose of $\mathrm{P} / \mathrm{R}$ during the lead-in phase were

Fig. 2 SVR12 according to fibrosis stage and prior response. All patients who received at least one dose of BOC included in the study.

$45.2 \%,(188 / 416), 55.1 \%$ in F3, (70/127) and $40.8 \%$ in F4, (118/289), respectively.

Figure S1 shows the rate of undetectable HCV-RNA at different week points during the full course of treatment and after its discontinuation. Figure 1 shows the overall EoTR, SVR12 and relapse rates, which were $62 \%, 49 \%$

Table 2 Predictors of treatment failure among patients with undetectable HCV-RNA at TW8 and of treatment success among those with detectable HCV-RNA at TW8

\begin{tabular}{|c|c|c|c|c|c|c|}
\hline & \multicolumn{2}{|l|}{ Overall } & \multicolumn{2}{|l|}{ F3 } & \multicolumn{2}{|l|}{$\mathrm{F} 4$} \\
\hline & No SVR & SVR & No SVR & SVR & No SVR & SVR \\
\hline \multicolumn{7}{|l|}{$\mathrm{TW}^{*}(\%)$} \\
\hline Detectable & $132(68.4)$ & $61(31.6)$ & $35(60.3)$ & $23(39.7)$ & $97(71.9)$ & $38(28.1)$ \\
\hline Undetectable & $44(27.7)$ & $115(72.3)$ & $11(20.0)$ & $44(80.0)$ & $33(31.7)$ & $71(68.3)$ \\
\hline PPV, \% & 72.3 & & 80.0 & & 68.3 & \\
\hline \multirow[t]{3}{*}{ NPV, \% } & 68.6 & & 60.3 & & 71.9 & \\
\hline & \multicolumn{2}{|l|}{ Overall } & \multicolumn{2}{|l|}{ F3 } & \multicolumn{2}{|l|}{ F4 } \\
\hline & No SVR & SVR & No SVR & SVR & No SVR & SVR \\
\hline \multicolumn{7}{|l|}{$\mathrm{TW}^{\dagger}(\%)$} \\
\hline$>1000$ & $44(91.7)$ & $4(8.3)$ & $13(100)$ & $0(0.0)$ & $30(90.9)$ & $3(9.1)$ \\
\hline$<1000$ & $131(43.4)$ & $171(56.6)$ & $33(33.0)$ & $67(67.0)$ & $99(48.3)$ & $106(51.7)$ \\
\hline PPV, \% & 56.6 & & 67.0 & & 51.7 & \\
\hline \multirow[t]{3}{*}{ NPV, \% } & 91.7 & & 100 & & 90.9 & \\
\hline & \multicolumn{2}{|l|}{ Overall } & \multicolumn{2}{|l|}{ F3 } & \multicolumn{2}{|l|}{$\mathrm{F} 4$} \\
\hline & No SVR & SVR & No SVR & SVR & No SVR & SVR \\
\hline \multicolumn{7}{|l|}{ TW8* $(\%)$} \\
\hline$<3$ log-decline & $26(89.7)$ & $3(10.3)$ & $12(92.3)$ & $1(7.7)$ & $14(87.5)$ & $2(12.5)$ \\
\hline$\geq 3$ log-decline & $148(46.5)$ & $170(53.5)$ & $34(34.0)$ & $66(66.0)$ & $114(52.3)$ & $104(47.7)$ \\
\hline PPV, \% & 53.5 & & 66.0 & & 47.7 & \\
\hline NPV, \% & 89.7 & & 92.3 & & 87.5 & \\
\hline
\end{tabular}

${ }^{*} \mathrm{HCV}-\mathrm{RNA}$ status is missing for 29 patients; ${ }^{\dagger} \mathrm{HCV}-\mathrm{RNA}$ evaluation is missing for 31 patients; ${ }^{\star}$ Log-decline. 
Table 3 Univariate and Multivariate analysis for SVR12

\begin{tabular}{|c|c|c|c|c|}
\hline Variable & Reference & $\begin{array}{l}\text { Univariate } \\
\text { RR }(95 \% \text { CI) }\end{array}$ & $\begin{array}{l}\text { Multivariate } \\
\text { RR }(95 \% \text { CI })\end{array}$ & $P$-value \\
\hline $\mathrm{TW} 8<1000 \mathrm{IU} / \mathrm{mL}$ & Undetectable & $3.97(2.45-6.41)$ & $4.22(2.49-7.16)$ & $<0.0001$ \\
\hline TW8 $\geq 1000 \geq 3$ log-decline & Undetectable & $47.0(6.10-362)$. & 40.29 (10.7-152.) & $<0.0001$ \\
\hline TW $8 \geq 1000<3$ log-decline & Undetectable & $32.7(7.42-143)$. & & \\
\hline TW4 $<1$ log-decline & $\geq 1$ log-decline & $3.53(2.04-6.11)$ & $2.75(1.23-6.14)$ & 0.01 \\
\hline TW4 1 log-decline & $<1$ log-decline & $0.47(0.26-0.86)$ & & \\
\hline TW4 2 log-decline & $<1$ log-decline & $0.24(0.12-0.46)$ & & \\
\hline TW4 3 log-decline & $<1$ log-decline & $0.18(0.08-0.44)$ & & \\
\hline TW4 4 log-decline & $<1$ log-decline & $0.06(0.02-0.23)$ & & \\
\hline TW4 5 log-decline & $<1$ log-decline & $0.05(0.01-0.24)$ & & \\
\hline TW4 log-decline (continuous) & Per log-decline & $0.54(0.44-0.65)$ & & \\
\hline Male & Female & $0.64(0.41-0.99)$ & & \\
\hline Age $\geq 60$ years & $<60$ years & $1.14(0.73-1.77)$ & & \\
\hline Metavir F4 & F3 & $1.65(1.07-2.55)$ & & \\
\hline Metavir F4 Child A6 & F4 - Child A5 & $3.55(1.48-8.52)$ & & \\
\hline FibroScan $(\geq 12.5 \mathrm{kPa})$ & $<12.5 \mathrm{kPa}$ & $1.65(1.05-2.60)$ & & \\
\hline FibroScan (continuous) & Per $1 \mathrm{kPa}$ & $1.04(1.02-1.07)$ & $1.05(1.02-1.09)$ & 0.003 \\
\hline Varices & F4 - No varices & $1.03(0.57-1.86)$ & & \\
\hline HCV genotype $1 b$ & $1 \mathrm{a}$ & $0.89(0.55-1.44)$ & & \\
\hline Prior null & Prior relapser & $2.60(1.62-4.17)$ & $2.06(1.24-3.44)$ & 0.004 \\
\hline Prior partial & Prior relapser & $1.55(0.90-2.66)$ & & \\
\hline Albumin $\leq 3.5 \mathrm{~g} / \mathrm{dL}$ & $>3.5 \mathrm{~g} / \mathrm{dL}$ & $4.80(1.78-12.9)$ & $5.16(1.67-16.0)$ & 0.004 \\
\hline $\mathrm{PLT} \leq 100 \quad 000 / \mu \mathrm{L}$ & $>100000 / \mu \mathrm{L}$ & $3.44(1.69-7.02)$ & $3.51(1.50-8.21)$ & 0.004 \\
\hline Baseline viral load >800 000 & $\leq 800000$ & $1.04(0.67-1.61)$ & - & \\
\hline
\end{tabular}

*Only variables for which the association remained statistically significant were included in the final multivariable logistic regression model (Back-wise variables selection). Bold values are statistically significant.

and $20 \%$, respectively. No difference was observed in EoTR rate between $\mathrm{F} 3$ and $\mathrm{F} 4$ patients, while SVR12 was significantly lower in cirrhotic patients $(P=0.02)$ due to the higher relapse rate $(P=0.01)$ in this latter group of patients. SVR12 rates by historical response and by fibrosis stage are shown in Fig. 2. As expected, SVR12 rate was higher in relapsers $(61.3 \%)$, compared to partial $(50.6 \%)$ and null $(37.9 \%)$ responders. None of the patients with concurrent low albumin levels and low platelet counts achieved SVR. Overall, a high proportion of patients $(72.3 \%)$ with undetectable HCV-RNA levels at treatmentweek (TW) 8 achieved SVR (PPV 72.3\%, 68.3\% in F4 and $80 \%$ in F3). On the contrary, very few patients $(4 / 48$, $8.3 \%$ with detectable TW8 HCV-RNA $\geq 1000 \mathrm{IU} / \mathrm{L}$ achieved SVR (NPV $=91.7 \%$, 90.9\% in $\mathrm{F} 4$ and $100 \%$ in F3) (Table 2).

Of interest, among 98 patients without a 1-log-decline in HCV-RNA at TW4, 20 had undetectable HCV-RNA and 29 had HCV-RNA $<1000 \mathrm{IU} / \mathrm{L}$ at TW8, respectively.

Several factors predicting the achievement of SVR, overall and by F3/F4, were identified with MLR. The factors identified were historical response to $\mathrm{P} / \mathrm{R}$ (relapser vs partial responder and null responder), fibroScan $(1 \mathrm{kPa}$ increase, as a continuous variable), platelet counts $(\leq 100000 / \mu \mathrm{L})$ and albumin levels $(\leq 3.5 \mathrm{~g} / \mathrm{dL})$, HCVRNA $\geq 1 \log _{10}$-decline from baseline at TW4, and undetectable HCV-RNA at TW8, which were all independently associated with SVR (Tables 3 and 4).

In both F3 and F4 patients, HCV-RNA at TW8 $\geq 1000 \mathrm{IU} / \mathrm{L}$ (undetectable HCV-RNA as the standard reference) was associated with the lowest likelihood of attaining SVR (95\% confidence interval (CI) 10.5-124; risk ratio (RR) 36.1, $P<0.0001$, Table 3). SVR12, according to TW8 HCV-RNA is illustrated in Fig. 3. As mentioned, residual viremia $>1000$ IU/L was associated with high likelihood of not achieving SVR, regardless of whether or not HCV-RNA $\geq 3$ log-decline was reached (Fig. 3). In particular, only 3 of 21 (14\%) patients with TW8 HCVRNA $>1000 \mathrm{IU} / \mathrm{mL}$ attained SVR, irrespective of having achieved HCV-RNA $\geq 3$ log-decline.

At TW8, 45.2\% (159/352) of patients had undetectable HCV-RNA. Baseline characteristics associated with a low likelihood to achieve this result were albumin levels and prior null response (Table S2). In addition, female gender, albumin levels and low platelet counts predicted treatment failure in this group of patients, while predictors of SVR in patients with HCV-RNA still detectable at TW8 


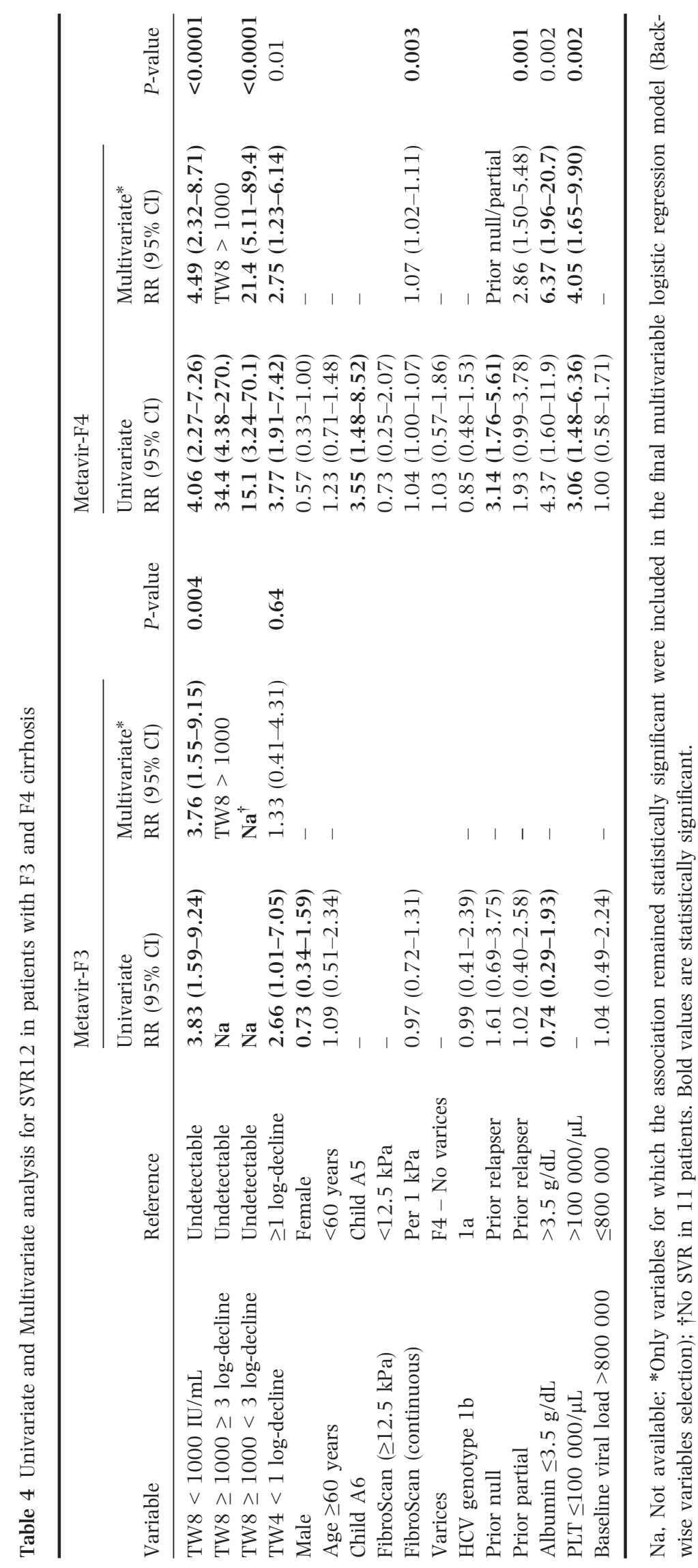

(C) 2014 John Wiley \& Sons Ltd 


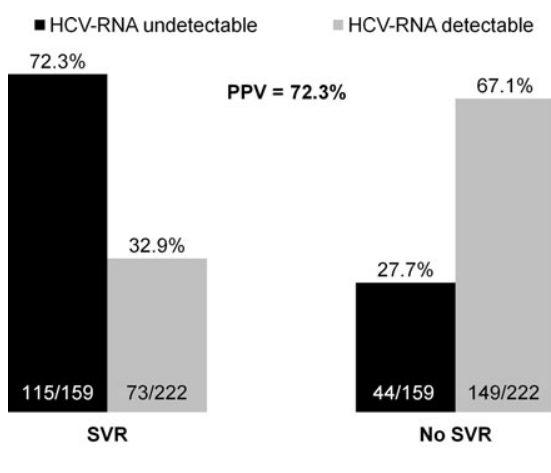

- HCV-RNA $<1000 \mathrm{UI} / \mathrm{mL}=\mathrm{HCV}-\mathrm{RNA}>1000 \mathrm{Ul} / \mathrm{mL}$

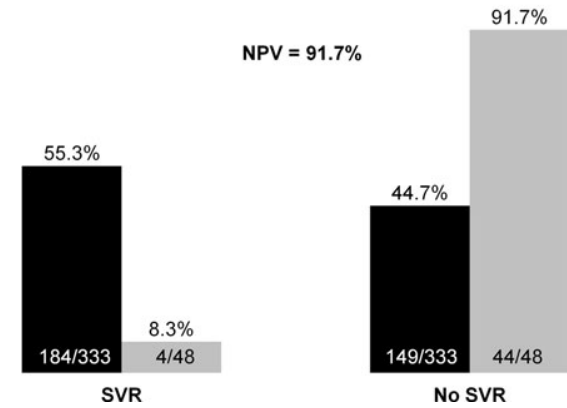

Fig. 3 SVR according to treatment-week 8 virological response. All patients who received at least one dose of BOC included in the study.

were Child class A5 vs A6, high albumin levels and high platelet counts, and favourable IL28B CC genotype (Table S3).

Table S4 shows the rate of SVR among the 159 patients with undetectable HCV-RNA at TW8 according to whether or not they had received a full course of treatment. Interestingly, 102 of 120 (85\%) subjects who completed the full course of treatment achieved SVR. Detailed information describes the reasons for early discontinuation of treatment as shown in Table S5.

\section{NNT calculation}

SVR12 and NNT for single SVR stratified by patient characteristics at time of entry, TW8 response and F3/F4 stages are reported in Table 5.

\section{Safety and tolerability}

Overall, 92 patients $(24.1 \%)$ withdrew from all treatments due to adverse events (Table 6). Serious adverse events (i.e. events that resulted in death were life threatening, resulted in persistent or clinically significant disability/incapacity or required hospitalization) occurred in $13.4 \%(51 / 381)$ of all patients. Overall, three patients died $(0.8 \%$; 0 in F3, 0 in $\mathrm{F} 4 / \mathrm{CP}$ A5 and $3(7.3 \%)$ in $\mathrm{F} 4 /$ CP A6) at weeks 6, 10 and 28. All deaths occurred in the F4 group of 289 patients (1\%) compared to 0 deaths in the group of $127 \mathrm{~F} 3$ patients. The cause of death was attributable, in all cases, to multiple organ failure following the onset of severe infection and generalized sepsis (Table 6). Overall, 11 patients $(2.9 \%)$ had hepatic decompensation, and all episodes were observed in cirrhotic patients $(3.8 \%)$. The frequency of serious adverse events was higher in patients with more advanced disease and in the Spanish cohort (Table S6). At MLR, Metavir F4,

Table 5 SVR12 and NNT in patients receiving at least one BOC dose according to baseline characteristics, fibrosis stage, historical response and TW8 HCVRNA value

\begin{tabular}{|c|c|c|c|c|c|c|c|c|c|}
\hline \multirow[b]{2}{*}{ Variable } & \multicolumn{3}{|l|}{ Total } & \multicolumn{3}{|c|}{ Metavir F3 } & \multicolumn{3}{|c|}{ Metavir F4 } \\
\hline & Patients & SVR (\%) & NNT & Patients & SVR (\%) & NNT & Patients & SVR (\%) & NNT \\
\hline All & 381 & $188(49.3)$ & 2.0 & 121 & $70(57.9)$ & 1.7 & 260 & $118(45.4)$ & 2.2 \\
\hline Italy & 267 & $128(47.9)$ & 2.1 & 100 & $57(57.0)$ & 1.8 & 167 & $71(42.5)$ & 2.4 \\
\hline Spain & 114 & $60(52.6)$ & 1.9 & 21 & $13(61.9)$ & 1.6 & 93 & $47(50.5)$ & 2.0 \\
\hline TW8 Undetectable & 159 & $115(72.3)$ & 1.4 & 55 & $44(80.0)$ & 1.3 & 104 & $71(68.3)$ & 1.5 \\
\hline TW8 < $1000 \mathrm{IU} / \mathrm{mL}$ & 143 & $56(39.2)$ & 2.6 & 43 & $22(51.2)$ & 2.0 & 100 & $34(34.0)$ & 2.9 \\
\hline TW8 $\geq 1000 \mathrm{IU} / \mathrm{mL}$ & 48 & $4(8.3)$ & 12.0 & 15 & $1(6.7)$ & 15.0 & 33 & $3(9.1)$ & 11.0 \\
\hline Prior relapser & 137 & $84(61.3)$ & 1.6 & 47 & $29(61.7)$ & 1.6 & 90 & $55(61.1)$ & 1.6 \\
\hline Prior partial & 89 & $45(50.6)$ & 2.0 & 31 & $19(61.3)$ & 1.6 & 58 & $26(44.8)$ & 2.2 \\
\hline Prior null & 153 & $58(37.9)$ & 2.6 & 42 & $21(50.0)$ & 2.0 & 111 & $37(33.3)$ & 3.0 \\
\hline FibroScan $<12.5 \mathrm{kPa}$ & 123 & $71(57.7)$ & 1.7 & 107 & $65(60.7)$ & 1.6 & 16 & $6(37.5)$ & 2.7 \\
\hline FibroScan $\geq 12.5 \mathrm{kPa}$ & 201 & $91(45.3)$ & 2.2 & - & & & 201 & $91(45.3)$ & 2.2 \\
\hline Albumin $>3.5 \mathrm{~g} / \mathrm{dL}$ & 329 & $168(51.1)$ & 2.0 & 99 & $56(56.6)$ & 1.8 & 230 & $112(48.7)$ & 2.1 \\
\hline Albumin $\leq 3.5 \mathrm{~g} / \mathrm{dL}$ & 28 & $5(17.9)$ & 5.6 & - & & & 28 & $5(17.9)$ & 5.6 \\
\hline 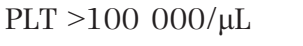 & 336 & $177(52.7)$ & 1.9 & 121 & $70(57.9)$ & 1.7 & 215 & $107(49.8)$ & 2.0 \\
\hline PLT $\leq 100000 / \mu \mathrm{L}$ & 45 & $11(24.4)$ & 4.1 & - & & & 45 & $11(24.4)$ & 4.1 \\
\hline
\end{tabular}

NNT, number needed to treat; None of the seven patients with both low albumin and low platelet counts had SVR. 
Table 6 Adverse events anytime during TW5-TW48 among 381 patients who received at least one dose of BOC

\begin{tabular}{lr}
\hline Adverse events during TW5-TW48 & $N(\%)$ \\
\hline Serious adverse events & $51(13.4)$ \\
Deaths & $3(0.8)$ \\
Sepsis, MOF & $4(1.1)$ \\
Infections & $43(11.3)$ \\
Hepatic decompensation & $11(2.9)$ \\
Haematological adverse events & $265(69.6)$ \\
Anaemia & \\
$\quad$ Grade $2-3(8.5<\mathrm{Hb}<10 \mathrm{~g} / \mathrm{dL})$ & $198(52.0)$ \\
$\quad$ Grade 4 (Hb $<8.5 \mathrm{~g} / \mathrm{dL})$ & $57(15.0)$ \\
Neutropaenia & $132(34.7)$ \\
$\quad$ Grade $3(500<N<750)$ & $46(12.1)$ \\
$\quad$ Grade $4(\mathrm{~N}<500)$ & $67(17.6)$ \\
Thrombocytopaenia & $6(1.6)$ \\
$\quad$ Grade $3(25$ 000 $<$ PLT $<50000)$ & \\
$\quad$ Grade 4 (PLT $<25$ 000) & $67(17.6)$ \\
Other events & $5(1.3)$ \\
Cutaneous adverse event & $11(2.9)$ \\
Cardiovascular adverse event & $60(15.8)$ \\
Cerebrovascular adverse event & $168(44.1)$ \\
Gastrointestinal adverse event & $32(8.4)$ \\
EPO & \\
Transfusions & \\
\hline
\end{tabular}

liver stiffness $\geq 12.5 \mathrm{kPa}$ and Child class A6 were independently associated with the occurrence of SAEs (Table 7). Two other strong predictors of SAEs during treatment with BOC were also lower platelet counts and lower albumin levels at baseline with an OR of 2.39 (95\% CI: 1.12-5.10) and of 3.42 (95\% CI: 1.45-8.08), respectively (Table 7). Details on hospitalization are summarized in Table S7. Approximately $70 \%$ of patients had bone marrow toxicity (Table 6). Table S8 shows the proportion of patients who required reduction of IFN, RBV or both. RBV dose reduction was associated with higher SVR rates $(P<0.003)$, while IFN reduction had no effect on SVR. In multivariate analysis, female gender, older age ( $>60$ years) and low platelet counts were associated with increased risk of haematological adverse events (Table 7).

\section{Resistance-associated variants}

NS3 genotype resistance testing by population sequencing was performed in 15 patients failing triple therapy with BOC $(3=$ GT- $1 \mathrm{a}, 11=\mathrm{GT}-1 \mathrm{~b}$ and $1=\mathrm{GT}-1 \mathrm{~g})$ and in 4 patients with early treatment discontinuation for adverse events ( $1=$ GT- 1 a and $3=$ GT- 1 b) (Table S9). Population sequencing of the viral protease was performed after a median (IQR) of $5(-5 ; 34)$ days from the time of treatment discontinuation or virological failure. Upon sequencing, HCV-RNA had median (IQR) values of 5.1
(3.8-5.0) $\log \mathrm{IU} / \mathrm{mL}$, ranging from 280 to $3002138 \mathrm{IU} / \mathrm{mL}$. Overall, at least one resistance-associated variant (RAV) was found in 12 of 15 patients analysed at the time of virological failure. In particular, in all patients that showed viral breakthrough during treatment $(N=3)$ or relapse after reaching the end of treatment $(N=4)$, the increase of viremia after achieving undetectable HCV-RNA was associated with RAVs occurrence (Table S9). Conversely, among the eight patients who discontinued treatment in accordance with BOC stopping rules, the de novo development of RAVs was exclusively observed in the 2 patients in whom the interruption was delayed by investigator decision and in 1 GT-1a patient presenting at baseline with the NS3 mutation Q80K. The remaining 5 patients who discontinued treatment after 12 weeks for virological failure did not show de novo development of RAVs. One of them was however infected by GT-1 g [24]. The characteristics of de novo RAV mutations within the 10 patients experiencing virological failure is described in Table S9. Among the 4 patients who prematurely discontinued treatment due to adverse events, 1 who delayed the discontinuation of treatment despite the futility rule showed de novo development of RAVs (R155K).

\section{DISCUSSION}

Boceprevir, in combination with $\mathrm{P} / \mathrm{R}$, was launched in September 2010. However, in several countries, it is still not available. Since then, with the exception of the US and few European countries, all other nations permitted this treatment only for patients with more advanced liver disease, mainly due to cost-containment measures. This limitation is expected to be maintained for at least the next 2 years in the vast majority of the world. In addition, it is well known that achieving an SVR reduces the risk of HCC, decompensation, and all-cause mortality in patients with cirrhosis [25-27]. Therefore, deferring access to therapy in these patients while waiting for all oral IFN-free regimens might not be an option. However, the safety concern reported in the CUPIC study [17], especially for patients with severe portal hypertension and deteriorated liver function as well as lacking data in patients with previous null response to $\mathrm{P} / \mathrm{R}$, suggest that additional, reliable information to optimize BOC-based treatment in daily practice is needed. Here, we show that, $50 \%$ of all F4 patients treated with BOC/P/R can achieve an SVR. SVR rates were particularly high $(69 \%)$ in patients with undetectable HCV-RNA at TW8, as previously reported in a smaller number of patients with such characteristics [18]; these patients accounted for almost half of all treated cirrhotic populations. Furthermore, F3 patients with undetectable viral load at TW8 achieved higher SVR rates (80\%). The reason why the rate of SVR in patients with F4 is lower, when compared to F3 subjects, is easily explained by the higher 
Table 7 Predictors of serious or haematological adverse events during treatment with BOC (week 5 to week 48)

\begin{tabular}{|c|c|c|c|c|}
\hline & \multicolumn{2}{|l|}{ Serious events } & \multicolumn{2}{|c|}{ Haematological events } \\
\hline & Events/patients (\%) & OR $(95 \% \mathrm{CI})$ & Events/patients (\%) & OR $(95 \% \mathrm{CI})$ \\
\hline \multicolumn{5}{|l|}{ Gender } \\
\hline Male & $33 / 270(12.2)$ & 1.00 & $176 / 270(65.2)$ & 1.00 \\
\hline Female & $18 / 111(16.2)$ & $1.39(0.75-2.59)$ & 89/111 (80.2) & $2.16(1.27-3.67)$ \\
\hline \multicolumn{5}{|l|}{ Age } \\
\hline$<50$ years & 10/103 (9.7) & 1.00 & $60 / 103(58.3)$ & 1.00 \\
\hline 50-59 years & $21 / 144(14.6)$ & $1.59(0.71-6.53)$ & $98 / 144(68.1)$ & $1.53(0.90-2.58)$ \\
\hline$\geq 60$ years & 19/127 (15.0) & $1.64(0.73-3.69)$ & $101 / 127(79.5)$ & $2.78(1.56-4.98)$ \\
\hline \multicolumn{5}{|l|}{ Metavir } \\
\hline F3 & $5 / 121(4.1)$ & 1.00 & $81 / 121(66.9)$ & 1.00 \\
\hline $\mathrm{F} 4$ & $46 / 260(17.7)$ & 4.99 (1.93-12.9) & $184 / 260(70.8)$ & $1.20(0.75-1.90)$ \\
\hline \multicolumn{5}{|l|}{ Child class (F4) } \\
\hline A5 & $35 / 220(15.9)$ & 1.00 & $155 / 220(70.5)$ & 1.00 \\
\hline A6 & $11 / 33(33.3)$ & $2.74(1.22-6.16)$ & $25 / 33(75.8)$ & $1.34(0.57-3.11)$ \\
\hline \multicolumn{5}{|l|}{ FibroScan } \\
\hline$<12.5 \mathrm{kPa}$ & $7 / 123(5.7)$ & 1.00 & $79 / 123(64.2)$ & 1.00 \\
\hline$\geq 12.5 \mathrm{kPa}$ & $37 / 201(18.4)$ & $3.74(1.61-8.67)$ & $145 / 201(72.1)$ & $1.44(0.89-2.33)$ \\
\hline Per $1 \mathrm{kPa}$ increase & & 1.03 (0.99-1.06) & & $1.03(0.99-1.06)$ \\
\hline \multicolumn{5}{|l|}{ Varices (F4) } \\
\hline No & 26/135 (19.3) & 1.00 & $94 / 135$ (69.6) & 1.00 \\
\hline Yes & $14 / 65(21.5)$ & $1.15(0.56-2.39)$ & $49 / 65(75.4)$ & $1.34(0.68-2.62)$ \\
\hline \multicolumn{5}{|l|}{ Genotype } \\
\hline $1 b$ & 40/296 (13.5) & 1.00 & 209/296 (70.6) & 1.00 \\
\hline $1 \mathrm{a}$ & $11 / 85(12.9)$ & $0.95(0.47-1.95)$ & $56 / 85(65.9)$ & $0.80(0.48-1.34)$ \\
\hline \multicolumn{5}{|l|}{ Albumin } \\
\hline$>3.5 \mathrm{~g} / \mathrm{dL}$ & $40 / 329(12.2)$ & 1.00 & $225 / 329(68.4)$ & 1.00 \\
\hline Low $(\leq 3.5 \mathrm{~g} / \mathrm{dL})$ & $11 / 52(21.2)$ & $3.42(1.45-8.08)$ & 40/52 (76.9) & $1.39(0.57-3.37)$ \\
\hline \multicolumn{5}{|l|}{ Platelets } \\
\hline$>100000 / \mu \mathrm{L}$ & $41 / 340(12.1)$ & 1.00 & $228 / 340(67.1)$ & 1.00 \\
\hline Low $(\leq 100000 / \mu \mathrm{L})$ & $10 / 41(24.4)$ & $2.39(1.12-5.10)$ & $37 / 41(90.2)$ & $5.13(1.79-14.7)$ \\
\hline \multicolumn{5}{|l|}{ Previous response } \\
\hline Relapser & $22 / 137(16.1)$ & 1.00 & 105/137 (76.6) & 1.00 \\
\hline Partial responder & $12 / 89(13.5)$ & $0.82(0.38-1.74)$ & $66 / 89(74.2)$ & $0.88(0.47-1.62)$ \\
\hline Null responder & 17/153 (11.1) & $0.65(0.33-1.29)$ & $94 / 153(61.4)$ & $0.49(0.29-0.81)$ \\
\hline
\end{tabular}

Bold values are statistically significant.

relapse rate observed in this latter group of patients. Additional information provided by this study is that in patients with undetectable HCV-RNA at TW8 who tolerated a full course of therapy, SVR was extremely high $(86 \%)$ and this finding was observed in more than two-third of this group of patients. Moreover, as there was no discontinuation related to virological breakthrough in this group of subjects, we may assume that the emergence of escape mutants was absent or very low.

Previously, it was reported that SVR was more likely in patients with advanced fibrosis/cirrhosis who had an HCVRNA decline $\geq 1.0$ log at week 4 (end of the lead-in phase with $\mathrm{P} / \mathrm{R}$ ) [18]. However, although this result was confirmed in our analysis, we found that approximately 50\% of patients with $<1 \mathrm{log}$-decline at TW 4 achieved undetect- able HCV-RNA or $<1000$ IU/L at TW8. This data supports the decision to start BOC therapy after the lead-in phase, to avoid missing several SVRs in this poor IFN-sensitive population.

Irrespective of the fibrosis stage, HCV-RNA $\geq 1000 \mathrm{IU} / \mathrm{L}$ at TW8 was associated with a negligible rate of SVR $(8 \%$, $\mathrm{NPV}=92 \%$ ). In agreement with the FDA and the European Commission (EC), which approved a revision of the BOC Prescribing Information, (i.e. a futility rule to stop therapy with $\mathrm{BOC} / \mathrm{P} / \mathrm{R}$ in all patients if TW8 HCV-RNA levels are $\geq 1000$ IU per $\mathrm{mL}$ was added), our results provide a solid validation in support of this decision.

Additional predictors of SVR for F4 patients in the MLR analysis included male gender, prior null response, low albumin levels and low platelet counts. Supplemen- 
tary information emerging from the study was that liver stiffness, the value of which was found to be associated with disease outcome [28], paralleled some well-established surrogate markers of disease severity and portal hypertension (i.e. Child class, platelet counts, and oesophageal varices) in predicting SVR. Consequently, this variable may be proposed, as a useful tool to identify the subgroup of patients not eligible for therapy with firstgeneration PIs.

Although the clinical characteristics of $\mathrm{F} 4$ patients treated with BOC/P/R in the French Early Access Programme were similar to those of patients in our study (median age was 56.8 vs 57.7 years, proportion of male patients was $67.9 \%$ vs $69.5 \%$ ), there were some differences between the two cohorts. First of all, null responders were originally excluded from the CUPIC study and, ultimately, $8 \%$ of these subjects were enroled. Moreover, both mean baseline platelet counts and serum albumin levels were lower in the BOC-CUPIC arm (144 000/ $\mu \mathrm{L}$ vs $165000 / \mu \mathrm{L}$ and 4.8 vs $4.0 \mathrm{~g} / \mathrm{dL}$, respectively) compared to patients enroled in our study, and NPP included $2.4 \%$ (vs $8.3 \%$ in CUPIC) of patients with concomitant low baseline albumin levels and platelet counts. Finally, the frequency of infection with HCV genotype 1 a was different (41\% vs $22.4 \%$ ). The proportion of patients with oesophageal varices was also similar $(37.6 \%$ vs $42 \%)$, but it should be noted that an upper gastrointestinal endoscopy was performed in only $51.4 \%$ of patients of the CUPIC population treated with BOC.

Despite these discrepancies, in agreement with the CUPIC study, we confirmed that the concurrent presence of low albumin levels and platelet counts at baseline was a strong predictor of poor response. Similarly, to the French study, our survey showed that poor TW8 response (i.e. HCV-RNA $<3$ log-decline compared to baseline) is associated with a low likelihood of SVR. Therefore, we may speculate that the two studies mutually validated themselves and may be considered complementary in enhancing the knowledge regarding this type of patients.

In summary, the present study provides the most detailed analysis ever carried out in the largest group of patients with advanced liver disease treated with BOC. The attained results enable clinicians to evaluate, in each single category of patients, predictors of both SVR (thus permitting the calculation of the NNT) and severe complications (both liver and haematological-related). The NNT in patients with undetectable HCV-RNA at TW8 is extremely favourable regardless of all negative baseline predictors. Moreover, using this new TW8 futility rule, which our study strongly validates, EPO and blood transfusions may be spared, and the hospitalization rate may be reduced, thus lowering the total cost of therapy. Finally, this may be a way for clinicians to not deny BOC triple therapy ' $a$ priori' to all IFN-eligible patients, and thus safely prevent exposure to an ineffective treatment in patients with a potential high rate of adverse events.

In conclusion, this analysis assessed potential benefits and risks of BOC treatment in a wide range of patients with advanced liver disease. Using a simple combination of baseline and on-treatment predictors, clinicians may easily identify patients with a high likelihood of achieving SVR and those at risk for severe complications. To fill the time gap until all oral DAAs become available, an eight-week BOC-based treatment may be proposed as a right option to assess tolerability and likelihood of success of this therapy in cirrhotic patients whose characteristics make them eligible for IFN-based regimens.

\section{ACKNOWLEDGEMENTS}

We thank Prof. CF Perno and his collaborators (M Aragri, FP Antonucci and VC di Maio, Virology Unit of 'Tor Vergata', University of Rome) for the HCV sequencing support. We are also highly indebted to J Petrovic, MD, formerly Merck director of Italian Medical Virology Unit.

\section{AUTHOR CONTRIBUTIONS}

All co-authors had full access to all pertinent data upon request. Each co-author has approved the final version of the manuscript. The corresponding authors had full access to all of the data and take full responsibility for the accuracy of the data and statistical analyses. The opinions expressed in this report represent the consensus of the authors and do not necessarily reflect the formal position of Merck or the authors' affiliated universities.

\section{FINANCIAL SUPPORT AND POTENTIAL COMPETING INTERESTS}

The provided results are independently assessed by all the investigators involved in the program, and no support was obtained by MSD, except for the compassionate use of drugs. The opinions expressed in this report represent the consensus of the authors. The corresponding authors had full access to all of the data and take full responsibility for the accuracy of the data and statistical analyses.

\section{REFERENCES}

1 Bourlière M, Wendt A, Fontaine $\mathrm{H}$ et al. How to optimize HCV therapy in genotype 1 patients with cirrhosis. Liver Int 2013; 33(Suppl 1): 46-55.
2 Chung RT, Baumert TF. Curing chronic hepatitis C- The arc of a medical triumph. $N$ Engl $J$ Med 2014; 370: 1576-1578.
3 Poordad F, McCone J Jr, Bacon BR et al. Boceprevir for untreated chronic HCV genotype 1 infection. N Engl J Med 2011; 364: 1195-1206. 
4 Bacon BR, Gordon SC, Lawitz E et al. Boceprevir for previously treated chronic HCV genotype 1 infection. N Engl J Med 2011; 364: 1207-1217.

5 Jacobson IM, McHutchison JG, Dusheiko G et al. Telaprevir for previously untreated chronic hepatitis C virus infection. N Engl J Med 2011; 364: 2405-2416.

6 Zeuzem S, Andreone P, Pol S et al. Telaprevir for retreatment of $\mathrm{HCV}$ infection. N Engl J Med 2011; 364: 2417-2428.

7 Manns MP, Vierling JM, Bacon BR et al. The combination of MK-5172, Peginterferon, and Ribavirin is effective in treatment-naive patients with hepatitis $\mathrm{C}$ virus genotype 1 infection without cirrhosis. Gastroenterology 2014; 147: 366-376 Epub ahed of print.

8 Afdahl N, Reddy KR, Nelson DR et al. Ledispavir and Sofosvubir for previously treated HCV genotype 1 infection. N Engl J Med 2014; 370: 1483-1493.

9 Sulkowski MS, Gardiner DF, Rodriguez-Torres M et al. Daclatasvir plus sofosbuvir for previously treated or untreated chronic HCV infection. $N$ Engl J Med 2014; 370: 211-222.

10 Poordad F, Hezode C, Trinh R et al. ABT-450/r-ombitasvir and dasabuvir with ribavirin for hepatitis $\mathrm{C}$ with cirrhosis. N Engl J Med 2014; 370 : 1973-1982 Epub ahead of print.

11 Zeuzem S, Soriano V, Asselah T et al. Faldaprevir and Deleobuvir for HCV genotype 1 infection. N Engl J Med 2013; 369: 630-639.

12 Lok AS, Gardiner DF, Hezode C et al. Randomized trial of daclatasvir and asunaprevir with or without Peg/IFN/RBV for hepatitis C virus genotype 1 null responders. J Нераtol 2014; 60: 490-499.

13 Vierling J, Davis M, Flamm S et al. Sustained virologic response (SVR) in prior peginterferon/ribavirin (PR) treatment failures after retreatment

\section{APPENDIX 1}

The Italian and Spanish (IAS)-BoC Study Group Investigators: Italy: V. Di Marco, M. Monti, G. Rizzardini, S. Landonio, M. Rizzetto, L. E. Lapini, V. Piazzolla, A. Picciotto, A. Alberti, L. Cavaletto, M. Koch, M. Massari, L. with Boceprevir (BOC) + PR: the Provide study interim results. Gastroenterology 2012; 142: Supplement 1-S-931.

14 Vierling JM, Davis M, Flamm S et al. Boceprevir for chronic HCV genotype 1 infection in patients with prior treatment failure to peginterferon/ribavirin, including prior null response. J Hepatol 2014; 60: 748756.

15 Vierling JM, Zeuzem S, Poordad F et al. Safety \& efficacy of Boceprevir/Peginterferon/Ribavirin for HCV G1 compensated cirrhotics: metaanalysis of 5 trials. J Hepatol 2014; 61: 200-209 Epub ahead of print.

16 Hézode C, Fontaine H, Dorival C et al. Triple therapy in treatment-experienced patients with HCV-cirrhosis in a multicentre cohort of the French Early Access Programme (ANRS CO20-CUPIC) - NCT01514890. J Hepatol 2013; 59: 434-441.

17 Hezode C, Fontaine H, Dorival C et al. Effectiveness of Telaprevir or Boceprevir in treatment-experienced patients with HCV genotype 1 infection and cirrhosis. Gastroenterology 2014; 147: 132-142 Epub ahead of print.

18 Bruno S, Vierling JM, Esteban R et al. Efficacy and safety of boceprevir plus peginterferon-ribavirin in patients with HCV G1 infection and advanced fibrosis/cirrhosis. J Hepatol 2013; 58: 479-487.

19 Iacobellis A, Siciliano M, Annicchiarico BE et al. Sustained virological responses following standard antiviral therapy in decompensated HCVinfected cirrhotic patients. Aliment Pharmacol Ther 2009; 30: 146-153.

20 Fevery B, Susser S, Lenz O et al. HCV-RNA quantification with different assays: implications for protease inhibitor-based response-guided therapy. Antivir Ther 2014; doi:10. 3851/IMP2760 Epub ahead of print.

Muratori, V. Cipriano, A. Montineri, C. Iacobello, S. Fangazio, M. Pirisi, A. Colombo, G. Bellati, F. Mazzotta, P. Pierotti, A. Traverso, G. Serviddio, M. Russello, T. Santantonio, D. Drenaggi, E. Marchionne, M. Zuin, M. Delliponti, F. Farina, P. Andreone, A.
21 Ogawa E, Furusyo N, Murata M et al. Early phase viral kinetics of chronic hepatitis C patients receiving telaprevir-based triple therapy: a comparison of two real-time PCR assays. Antiviral Res 2013; 99: 119-124.

22 Foucher J, Chanteloup E, Vergniol J et al. Diagnosis of cirrhosis by transient elastography (FibroScan): a prospective study. Gut 2006; 55: 403-408.

23 Castera L, Forns X, Alberti A. Noninvasive evaluation of liver fibrosis using transient elastography. J Нерatol 2008; 48: 835-847.

24 Cento V, Landonio S, De Luca F et al. A boceprevir failure in a patient infected with HCV-genotype $1 \mathrm{~g}$ : importance and limitations of virus genotyping prior to HCV protease inhibitor-based therapy. Antivir Ther 2013; 18(4): 645-648.

25 Bruno S, Stroffolini T, Colombo M et al. Sustained virological response to interferon-alpha is associated with improved outcome in HCV-related cirrhosis: a retrospective study. Hepatology 2007; 45: 579-587.

26 Aleman S, Rahbin N, Weiland O et al. A risk for hepatocellular carcinoma persists long-term after sustained virologic response in patients with hepatitis C-associated liver cirrhosis. Clin Infect Dis 2013; 57: 230-236.

27 Van der Meer AJ, Veldt BJ, Feld JJ et al. Association between sustained virological response and all-cause mortality among patients with chronic hepatitis $\mathrm{C}$ and advanced hepatic fibrosis. JAMA 2012; 308: 2584-2593.

28 Vergniol J, Foucher J, Terrebonne E et al. Non invasive test for fibrosis and liver stiffness predict 5-year outcomes of patients with chronic hepatitis C. Gastroenterology 2011; 140: 1970-1979.

Scuteri, M. Galli, E. G. Giannini, A. Nerli, S. Carbonai, N. Coppola, M. Montalbano, V. Portelli, A. Di Biagio, L. A. Nicolini, C. Mastroianni, S. Madonia, A. Licata, G. Montalto, L. Giannitrapani, M. Mondelli, A. Pellicelli, P. Toniutto, G. Borgia, I. Gen- 
tile, M. De Luca, G. G. Di Costanzo, G. Corti, V Cento; Spain: M. Sousa, M. B. Delgado, J. De la Revilla, J. M. Navarro, R. Barcena, M. Romero-Go-

\section{SUPPORTING INFORMATION}

Additional Supporting Information may be found in the online version of this article:

Figure S1: Virological response during treatment and 12 weeks follow-up. All patients who received at least one dose of BOC included in the study. Table S1: Baseline patient characteristics at study entry, according to country of origin.

Table S2: Baseline predictors of HCV-RNA undetectable at TW8. mez, C. M. Fernandez-Rodriguez, I. Narvaez, J. C. Erdozain, E. Molina, I. Fernandez, B. Cuenca, R. Planas, J. Garcia-Samaniego, J. M. Ladero, J. M.

Table S3: Predictors of treatment failure (no SVR) in patients with undetectable HCV-RNA at TW8 or treatment success (SVR) in patients with detectable HCV-RNA at TW8.

Table S4: Details of patients with undetectable HCV-RNA at week 8.

Table S5: Treatment course and status of 381 patients who received at least one dose of BOC.

Table S6: Adverse events anytime during TW5-TW48 among 381
Gonzalez, M. A. Serra, I. Castellote, R. Sola, T. Anton, I. Ryan, F. Gonzalez, E. Martinez, J. Portu.

patients who received at least 1 dose of BOC.

Table S7: Hospitalization (41 in 36 patients).

Table S8: SVR according to Ribavirin and Peg/IFN reduction or interruption.

Table S9: NS3 genotypic resistance test in patients experiencing virological failure or early discontinuation of treatment administration. 